\title{
Contribuições da Engenharia Didática e da técnica de ladrilhamento no desenvolvimento de um curso direcionado para acadêmicos de Licenciatura em
}

\section{Matemática}

\author{
Contributions of Didactic Engineering and the technique of tiling in the development of a course \\ aimed at undergraduate students in Mathematics \\ Aportes de la Ingeniería Didáctica y la técnica del alicatado en el desarrollo de un curso dirigido a \\ estudiantes de pregrado en Matematicas
}

Recebido: 06/06/2021 | Revisado: 14/06/2021 | Aceito: 16/06/2021 | Publicado: 28/06/2021

\author{
Josiane Martins Martins \\ ORCID: https://orcid.org/0000-0002-9646-6766 \\ Universidade Federal do Pampa, Brasil \\ E-mail: josianemartins @unipampa.edu.br \\ Cristiano Corrêa Ferreira \\ ORCID: https://orcid.org/0000-0002-7676-9233 \\ Universidade Federal do Pampa, Brasil \\ E-mail: cristianoferreira@unipampa.edu.br \\ Sonia Maria da Silva Junqueira \\ ORCID: https://orcid.org/0000-0002-5616-5344 \\ Universidade Federal do Pampa, Brasil \\ E-mail: soniajunqueira@unipampa.edu.br
}

\begin{abstract}
Resumo
Este trabalho é um recorte de uma pesquisa de mestrado que está vinculado ao projeto intitulado “ Investigações Matemáticas e Interdisciplinares em Projetos de Aprendizagens". A presente pesquisa relata o desenvolvimento de um curso concebido durante a pandemia COVID19 e, por esse motivo, estruturado em ambiente virtual, com atividades remotas no software Geogebra Book e síncronas no Google Meet. O propósito do curso é de estimular formas de explorar princípios e generalização de padrões a partir da composição de polígonos no plano por meio da técnica do ladrilhamento. O público alvo são acadêmicos do curso de matemática-licenciatura matriculados no sexto semestre do curso. O objetivo do artigo é analisar a performance de 2 acadêmicos quando submetidos a uma atividade de ladrilhamento por meio de uma engenharia didática. A concepção teórica-metodológica-conceitual é a Engenharia Didática, por meio da qual foram desenvolvidas as seguintes fases: análises prévias; concepção e análise a priori; experimentação, análise a posteriori e validação. Os resultados mostraram que a E.D. contribuiu para a ampliação e construção de conhecimento matemático geométrico, pois foi possível detectar que os acadêmicos compreendem de forma contextualizada a relação entre elementos de um polígono regular e sua aplicação na técnica de ladrilhamentos, assim como foram capazes de realizar conjecturas e generalizações representáveis por meio de afirmações e fórmulas. Palavras-chave: Engenharia didática; Geometria plana; Ladrilhamento; Polígonos regulares.
\end{abstract}

\begin{abstract}
This work is an excerpt from a master's research that is linked to the project entitled "Mathematical and Interdisciplinary Investigations in Learning Projects". This research reports the development of a course conceived during the COVID19 pandemic and, for this reason, structured in a virtual environment, with remote activities in Geogebra Book software and synchronous in Google Meet. The purpose of the course is to encourage ways to explore principles and generalization of patterns from the composition of polygons in the plane through the technique of tiling. The target audience is academics from the undergraduate mathematics course enrolled in the sixth semester of the course. The objective of the article is to analyze the performance of 2 academics when submitted to a tiling activity through a didactic engineering. The theoretical-methodological-conceptual conception is Didactic Engineering, through which the following phases were developed: previous analyses; design and a priori analysis; experimentation, a posteriori analysis and validation. The results showed that E.D. contributed to the expansion and construction of geometric mathematical knowledge, as it was possible to detect that academics understand in a contextualized way the relationship between elements of a regular polygon and their application in the tiling technique, as well as being able to make conjectures and generalizations representable through of statements and formulas.
\end{abstract}

Keywords: Didactic engineering; Plane geometry; Tiles; Regular polygons. 


\begin{abstract}
Resumen
Este trabajo es un extracto de una investigación de maestría que está vinculada al proyecto titulado "Investigaciones matemáticas e interdisciplinarias en proyectos de aprendizaje". Esta investigación reporta el desarrollo de un curso concebido durante la pandemia COVID19 y, por tal motivo, estructurado en un entorno virtual, con actividades remotas en el software Geogebra Book y sincrónicas en Google Meet. El propósito del curso es fomentar formas de explorar principios y generalización de patrones a partir de la composición de polígonos en el plano a través de la técnica del mosaico. El público objetivo son los académicos del curso de matemáticas de pregrado matriculados en el sexto semestre del curso. El objetivo del artículo es analizar el desempeño de 2 académicos sometidos a una actividad de mosaico mediante una ingeniería didáctica. La concepción teórico-metodológica-conceptual es la Ingeniería Didáctica, a través de la cual se desarrollaron las siguientes fases: análisis previos; diseño y análisis a priori; experimentación, análisis a posteriori y validación. Los resultados mostraron que E.D. contribuyó a la expansión y construcción del conocimiento matemático geométrico, ya que fue posible detectar que los académicos comprenden de manera contextualizada la relación entre elementos de un polígono regular y su aplicación en la técnica del mosaico, además de poder hacer conjeturas y generalizaciones representable a través de declaraciones y fórmulas.

Palabras clave: Ingeniería didáctica; Geometria plana; Losas; Polígonos regulares.
\end{abstract}

\title{
1. Introdução
}

A problemática descrita neste artigo diz respeito às dificuldades de estudantes em relação à compreensão de relações e conceitos próprios da Geometria Plana quanto aos elementos e características de polígonos regulares. Além do pouco aprofundamento do conteúdo na matemática escolar e da falta de contextualização desse ensino com a realidade dos estudantes, essas particularidades do estudo da Geometria são implicadores diretos na prática pedagógica de professores de matemática, portanto, tornam-se objetos de investigação em pesquisas na área da Educação Matemática. Essa problemática pode ser confirmada nos estudos de Teixeira (2018) e Stefani et al. (2019), que apontam para as dificuldades enfrentadas pelos professores em ministrarem os conteúdos de geometria, além de Afini et al. (2013) e Zanella et al. (2018) que sugerem o uso de softwares de geometria dinâmica para auxiliar a compreensão dos conceitos e propriedades dos objetos geométricos.

Diante do exposto, esta pesquisa se desenvolve, vinculada ao projeto de pesquisa Investigações matemáticas e interdisciplinares em projetos de aprendizagens (IMIPA), por meio da aplicação da técnica de Ladrilhamentos como proposta de contribuição para reduzir a problemática da compreensão de conceitos relacionados ao estudo de polígonos regulares e da composição dos pressupostos matemáticos que estão por trás dos ladrilhamentos possíveis e que atendem às regras do bom comportamento na Geometria Plana.

A definição de Ladrilhamento consiste em cobrir inteiramente um plano sem superposições de figuras e de espaços vazios entre eles. Essa técnica possibilita que o estudante investigue e participe de forma ativa no seu aprendizado, por exemplo, ao reconhecer os padrões, os tipos e composições de polígonos nos ladrilhos, bem como investigar e estabelecer relações entre ângulos internos e externos de um polígono, conforme Santos (2006).

A proposta metodológica utilizada é a Engenharia Didática (ED), sob a perspectiva de Artigue (1995). Essa metodologia permite que a pesquisadora entenda, planeje e analise as contribuições que a fase da experimentação proporcionará com a técnica de ladrilhamentos. A Engenharia Didática se divide em quatro fases: pesquisa preliminar; concepção e análise a priori; experimentação e análise a posteriori e validação, que foram tomadas como suporte na condução desta pesquisa.

Sendo assim, espera-se responder, ao longo da pesquisa, à seguinte questão: “A utilização da Engenharia Didática aliada à técnica de ladrilhamentos contribui para a realização de conjecturas e generalizações de padrões matemáticos a partir da composição de polígonos regulares?”

Para responder a essa questão, estruturou-se o trabalho da seguinte forma: na seção 1, apresenta-se a introdução; na seção 2, a reflexão teórica sobre engenharia didática; na seção 3, a metodologia; a seção 4 mostra os resultados e discussão e, por fim, na seção 5, as considerações finais. 


\section{Reflexões Teóricas e Estudos Relacionados}

A Engenharia Didática (ED) surgiu na década de 80, a fim de analisar situações didáticas no campo da Educação matemática. A ED caracteriza-se pela sua estrutura experimental baseada em sala de aula, ou seja, desde a elaboração, observação e análise de sequências de ensino. Divide-se em quatro fases, sendo elas: análise preliminar; concepção e análise a priori das situações didáticas; experimentação; e por fim, análise a posteriori e validação.

A primeira fase, análise preliminar, segundo Machado (2012), é aquela na qual são realizadas as observações do quadro teórico didático geral, assim como são feitas as análises do ensino atual e a aplicação dos conteúdos no ensino, além de averiguar as dificuldades e empecilhos no aprendizado do aluno. Para Artigue (1995), essa etapa distingue-se em três dimensões: Epistemológica, Cognitiva e Didática. A primeira, epistemológica, associa-se às características do conhecimento, ou seja, relacionada ao conteúdo transmitido. A segunda, cognitiva, associa-se às características cognitivas do público a quem é direcionado, ou seja, aos alunos aos quais é direcionada a pesquisa. A terceira, e última, dimensão didática, associa-se às características do funcionamento do sistema de ensino, ou seja, está relacionada ao sistema de ensino vigente.

A segunda fase, concepção e análise a priori das situações didáticas, segundo Artigue (1995), é caracterizada por delimitar variáveis de comando, isto é, a partir das análises preliminares escolhem-se as variáveis que são distinguidas em: macrodidáticas ou globais e as microdidáticas ou locais. Para Artigue (1995), as macrodidáticas referem-se aos recursos que serão utilizados, a retomada do estudo no assunto que se almeja ensinar, destacando a forma que será feita e, também, os métodos que serão utilizados no estudo qualitativo, também é necessário conhecer quais requisitos são necessários para ensinar o que se pretende. Já as microdidáticas referem-se, principalmente, às dificuldades encontradas no interior da sala de aula.

Para Machado (2012), essa fase embasa-se na Teoria das Situações Didáticas (TSD), ou seja, busca controlar as relações de sentido e situações. Portanto, nessa fase, ela se caracteriza tanto pela escolha das variáveis quanto pela previsão dos possíveis comportamentos dos alunos, o que possibilita controlar os possíveis problemas, permitindo que os alunos desenvolvam o conhecimento esperado. Para Almouloud (2007), essa fase proporciona, a partir do estudo da primeira fase, elaborar e analisar a sequência de situações-problema, ou seja, questões abertas e/ou fechadas que envolvem conhecimento matemático, essas serão aplicadas na fase da experimentação.

A terceira fase, experimentação, segundo Machado (2012), trata-se de aplicar a uma quantidade limitada de alunos instrumentos de pesquisa, onde se registram as observações, através de audiovisuais e relatórios realizados durante a experimentação. Para Almouloud (2007), nessa fase é necessário apresentar o organograma de trabalho, o cronograma do experimento, além de detalhar o cenário, as condições da experimentação, assim como é necessário justificar a questão e hipótese de pesquisa em relação ao experimento e, também, discutir os quadros teóricos e os objetivos.

Na última fase, análise a posteriori e validação, segundo Machado (2012), recolhem-se os dados e as observações feitas durante a experimentação. Já para Almouloud (2007), essa fase caracteriza-se por confrontar a análise a posteriori e validação com a priori em relação às hipóteses, problemática e os fundamentos teóricos.

A técnica utilizada para esse trabalho foi a dos ladrilhamentos e, nesse sentido, Sallum (2016) destaca que as primeiras peças de ladrilhos foram encontradas no Egito há cerca de 5000 anos a. C. Já Júlio et al. (2018) acrescenta que os ladrilhos formam a pavimentação do plano, através do revestimento de uma região plana sem que haja espaço ou sobreposição entre os polígonos.

Nos últimos anos, autores destacaram em suas pesquisas atividades relacionadas a ladrilhamentos, como é o exemplo de Mello (2015), que trabalhou com possíveis ladrilhamentos no plano com polígonos regulares, respeitando seus conceitos e o 
Teorema de Kepler ${ }^{1}$, em estudantes do terceiro ano do Ensino Médio. Júlio et al. (2018) destacaram que os ladrilhamentos, na educação matemática, foram inspirados nos elementos dos Parâmetros Curriculares Nacionais (PCN). Dessa forma, os autores apresentam um produto educacional para formação inicial e continuada para professores dos anos finais do Ensino Fundamental. Gumieri (2018) explora conceitos de ângulos internos e externos de polígonos regulares, utilizando o ladrilhamento no plano em alunos do Ensino Fundamental, com o objetivo de estimular o interesse em investigar o campo geométrico.

Zanella et al. (2018) destacam que essas ferramentas educacionais com a utilização de ambientes de geometria dinâmica como softwares, auxiliam e potencializam a compreensão dos objetos geométricos, seus conceitos e propriedades, no qual o estudante pode construir e manipular as representações geométricas, além de compreender os elementos das figuras. Os autores relatam também que a utilização de softwares, como Geogebra, possibilita que a construção de apenas uma figura serve para inúmeros testes, diferentemente quando são utilizados a régua e o compasso. Em síntese, constataram que a utilização do Geogebra foi relevante porque ficou evidente a compreensão das diferentes representações semióticas a partir das múltiplas representações dinâmicas.

Por meio dessa reflexão, pode-se verificar que a metodologia da Engenharia didática aliada à técnica do ladrilhamento em meio digital, com o uso do software Geogebra, estabelecem relações que poderão potencializar o aprendizado dos princípios e generalizações de padrões a partir da composição de polígonos no plano.

\section{Metodologia}

A metodologia da pesquisa é de natureza qualitativa e descritiva (Bogdan \& Biklen, 1994; Gil, 2002). Como técnica, para desenvolver o curso em análise neste artigo, serão aplicadas as quatro fases da E.D. Com base nos objetivos, toma-se a pesquisa do tipo descritiva, da qual cabe considerar o conhecimento do objeto em estudo por parte do pesquisador, gerado a partir de resultados de pesquisas (Gil, 2002). Nesse tipo de pesquisa, recorre-se à descrição de processos, mecanismos e relacionamentos que se mostram na realidade do fenômeno estudado.

Bogdan e Biklen (1994) transcrevem habilmente as características da investigação qualitativa e trazem as seguintes considerações: os materiais produzidos devem ser revistos na totalidade pelo investigador pois, são os instrumentos chave da análise, da mesma forma, apontam que os investigadores qualitativos entendem que as ações podem ser melhor compreendidas quando são observados no ambiente de ocorrência. Um outro aspecto a considerar é, que quando a investigação qualitativa é descritiva, os investigadores necessitam analisar os dados em toda a sua riqueza, respeitando, a forma como estes foram registrados ou transcritos, bem como, são previstos que nesse tipo de investigação ocorra naturalmente um interesse maior pelo processo do que simplesmente pelo resultado.

Nessa direção, na pesquisa qualitativa não há quantificações ou técnicas estatísticas de qualquer natureza, pois essa abordagem busca, com base em dados qualificáveis, compreender a realidade de determinados fenômenos, a partir da percepção dos diversos atores sociais (Gil, 2002).

Em síntese, a pesquisa qualitativa desenvolvida neste estudo envolveu a obtenção de dados a partir das produções geradas pelos acadêmicos em respostas a atividades propostas na fase de experimentação, terceira fase da ED, assim como a questões encaminhadas em questionários nas fases análise à priori e análise à posteriori, segunda e quarta fases da ED, respectivamente.

\footnotetext{
${ }^{1}$ Nesta pesquisa de Teorema de Kepler refere-se a obra que explorou três aspectos: geometria, música e astronomia no qual apresentou como resultado que existem exatamente onze maneiras de cobrir o plano utilizando- se exclusivamente polígonos regulares sujeitos a condições de bom comportamento.
} 


\subsection{Sujeitos e local da pesquisa}

Os sujeitos da pesquisa são acadêmicos do curso de Matemática-Licenciatura do campus Bagé, da UNIPAMPA. O curso foi iniciado com doze acadêmicos, e ocorreu nos meses de fevereiro e março de 2021. Desse número inicial de participantes, 9 concluíram todas as etapas do curso. Contudo, para este artigo especificamente, foram analisados os resultados produzidos por 2 dos 9 participantes.

Devido à pandemia de covid-19, que impôs necessidade de distanciamento físico e proibição de acesso ao campus para atividades presenciais, as atividades síncronas do curso foram realizadas por meio das plataformas Google Meet e Geogebra Book, para compartilhamento e realização das atividades síncronas.

\subsection{As fases da pesquisa}

As quatro fases da Engenharia didática serão tomadas como campo de organização, categorização e análise neste estudo, são elas: análise preliminar; concepção e análise a priori; experimentação e análise a posteriori e validação.

$\mathrm{Na}$ análise preliminar foram realizadas pesquisas a artigos, livros e dissertações sobre o assunto Geometria Plana, com a finalidade de entender os obstáculos encontrados na educação Básica e Superior, bem como de compreender as principais ações realizadas pelos professores no planejamento das atividades desenvolvidas em sala de aula. Essa fase foi subdivida em aspectos epistemológicos, didáticos e cognitivos.

Em relação aos aspectos epistemológicos, foram investigadas as principais dificuldades e empecilhos encontrados para a aprendizagem da Geometria Plana no decorrer do ensino básico, na sala de aula e na área de Geometria Plana, destacando-se os estudos de Pereira (2017), Teixeira (2018), Penteado et al. (2019), Stefani et al. (2019).

Em relação aos aspectos didáticos, foram estudados os documentos Projeto Pedagógico do Curso de Matemática (PPC) e o texto da BNC formação (2019) e a Base Nacional Comum Curricular (BNCC) para o Ensino Médio (Brasil, 2017), a fim de compreender aspectos curriculares que envolvem a formação do futuro educador matemático. Foram estudadas também sequências didáticas relativas ao tema ladrilhamentos, dentre as quais, destacam-se Martins (2018), Caetano (2010) e o caderno do professor de matemática (São Paulo, 2009).

Em relação aos aspectos cognitivos, foram estudadas as práticas desenvolvidas em sala de aula. Essa etapa permitiu perceber a importância de práticas pedagógicas que resultem na construção do conhecimento de forma ativa, pois refletem a autonomia em processos de aprendizagem. Destacam-se nessa fase os estudos de Afini et al. (2013), Teixeira (2018) e Zanella et al. (2018), em razão da utilização de softwares matemáticos, do trabalho com objetos do cotidiano, e das contribuições que apontam no aprendizado da matemática.

$\mathrm{Na}$ fase concepção e análise a priori, foram elaboradas hipóteses e as sequências didáticas, assim como destacadas as variáveis micro e macro didáticas. Também, nessa fase, constatou-se as possíveis resoluções da sequência didática elaborada. Como hipótese principal, destaca-se que: "Através das atividades com a técnica de ladrilhamentos, o acadêmico é capaz de se aprofundar em conteúdos referentes à Geometria Plana”. Quanto às variáveis Macrodidáticas (relacionadas à organização global), entende-se: a) ensino de conceitos de Geometria Plana; b) ênfase nas dificuldades de aprendizagem dos conceitos; e c) diferentes formas de ensino da Geometria Plana.

E como variáveis Microdidáticas (relativas à organização local), consideram-se: a) livro dinâmico no Geogebra Book, construído de forma compartilhada com os acadêmicos; b) manipulação de polígonos regulares no Geogebra para resolução de problemas de ladrilhamento; c) construção e reprodução de conceitos relacionados à Geometria Plana na construção de ladrilhamentos.

$\mathrm{Na}$ fase da experimentação, a aplicação da sequência didática, por meio do curso de ladrilhamento, caracterizou o experimento, destacando-se atividades em que a descoberta e investigação matemática foram necessárias para o encontro de 
conjecturas e exploração de conceitos.

A experimentação, contudo, foi antecedida por dois momentos de exposição pela pesquisadora, em que se apresentou a história e exemplos de ladrilhamentos e o uso das ferramentas do Geogebra, ambos foram realizados com apoio de vídeos elaborados pela pesquisadora. Considerou-se que essas atividades pré-experimento foram relevantes e necessárias, em virtude da contextualização sobre o tema e da familiarização com os recursos do Geogebra, pois refletem diretamente na etapa da experimentação, propriamente dita. Na experimentação, portanto, foi solicitado inicialmente que os acadêmicos respondessem quatro questões, em que também deveriam construir polígonos regulares, a partir do número de vértices e nomeá-los. Em seguida, deveriam achar os ângulos de todos os polígonos construídos, assim como as medidas de cada lado, e por fim, deveriam responder o que conseguiram observar com a atividade, permitindo que pudessem fazer conjecturas e estabelecer relações entre conceitos. A fase da experimentação ocorreu em quatro encontros.

Dessa forma, iniciou-se o novo encontro, dividindo-os novamente em dois momentos. O primeiro, tratou da manipulação e exercícios de ladrilhamentos, em que os acadêmicos utilizaram os polígonos construídos pelos autores no Geogebra, para manipulação e apoio na resolução dos problemas propostos. No primeiro momento, as questões envolviam encontrar quantos e quais foram os padrões de ladrilhamentos com ladrilhos iguais e com ladrilhos diferentes, e qual o princípio utilizado para preencher um ladrilhamento. No segundo momento, o conceito de ladrilhamentos bem-comportados foi apresentado aos acadêmicos, para em seguida serem propostos os seguintes questionamentos: Se todos os ladrilhamentos encontrados eram bem-comportados? Quais foram os ladrilhamentos que não atenderam às três regras de bom comportamento? Para fundamentar as respostas foram exigidas justificativas e, também era necessário citar exemplos e locais de ladrilhamentos bem-comportados.

No terceiro encontro, ocorreu a seção exploração dos conceitos matemáticos, com a finalidade de levar os acadêmicos a descobrir a generalização de fórmulas, como a soma dos ângulos internos e externos de um polígono, além de outras relações matemáticas envolvendo ângulo e número de lados de polígonos regulares. Depois dessa incursão, os acadêmicos foram questionados sobre quais e quantas são as combinações de ladrilhos regulares que preenchem perfeitamente o plano, e por fim, provocados a definir o conceito de ladrilhamento.

No quarto e último encontro, a pesquisadora destacou e resumiu todos os pontos importantes dos encontros anteriores e fez um fechamento das atividades, apresentando um vídeo que explicava o conceito de ladrilhamento. Em seguida, os acadêmicos foram solicitados a responder a um questionário pós-experimento, a fim de saber se a experimentação foi interessante no seu processo de aprendizagem. Basicamente, foi explorado por meio do questionário o que eles acharam das aulas sobre ladrilhamentos e geometria, se acharam fácil ou encontraram dificuldades nas atividades, se a técnica de ladrilhamento facilita a compreensão de conceitos da Geometria Plana e se o software Geogebra ajudou na compreensão de tais conceitos.

Por fim, na quarta fase da ED, tem-se a análise a posteriori e validação, que foi realizada por meio da comparação das respostas previstas na análise a priori com os resultados obtidos na experimentação.

A seguir, no âmbito da análise e resultados, tem-se a apresentação detalhada da quarta fase da ED, em que será mostrado se os objetivos foram alcançados e se o experimento realizado contribuiu para a validação da pesquisa.

\section{Resultados e Discussão}

Compõem esta seção, as observações e discussões relativas às descrições provenientes da fase de experimentação, a argumentação a partir da comparação entre os questionários iniciais e finais aplicados nesta E.D. com o propósito de apresentar resultados capazes de validar ou refutar as hipóteses desta pesquisa. Nesse sentido, os resultados e discussões serão organizados a partir dos quatro encontros conduzidos no processo de experimentação e das interações realizadas com os 
participantes auto identificados pelos pseudônimos de Lastonico e Gauss.

\subsection{Encontro 1}

No primeiro encontro, os participantes foram estimulados a indicar quais tipos de ladrilhamentos conheciam, a partir da atividade História e exemplos de ladrilhamentos. Foi apresentada a seguinte questão aos participantes: Através de suas lembranças do dia a dia, descreva e/ou desenhe quais ladrilhamentos você conhece?

O participante Lastonico respondeu que "são sempre polígonos, mais comum é serem quadrados", enquanto o participante Gauss respondeu, "Conheço alguns ladrilhos triangulares e muitos que são quadrangulares. Eu identifico alguns nas calçadas de praças, e também em prédios históricos da cidade de Bagé/RS". As respostas dos dois participantes além da relação imediata com o cotidiano, como era esperado a partir da formulação da questão, mostrou que ambos reconhecem elementos da Geometria Plana nos ladrilhamentos, pois mencionam expressões como quadrados, triângulos, quadrangulares, em vez de expressões que remetam a ideia de pisos e lajotas.

$\mathrm{Na}$ segunda questão, foram perguntados: Por que é usual utilizar polígonos regulares iguais no ladrilhamento da cobertura dos pisos? E o que essa técnica contribui na construção de casas e prédios? Lastonico respondeu que essa técnica "Economiza material porque preenche sem deixar espaços", enquanto Gauss destacou que "Isso porque todos os polígonos regulares pavimentam um plano, ou seja, eles conseguem preencher um plano sem se sobrepor. Aliás, são apenas aqueles polígonos que tenham o ângulo divisor de $360^{\circ}$, como o hexágono, quadrado e triângulo equilátero. Assim é possível cobrir o plano, e obter lindos padrões, por isso, esse tipo de figura é muito procurada por ceramistas e fabricantes de azulejos".

É possível inferir que as respostas dos dois participantes demonstram conhecimento sobre a técnica do ladrilhamento, uma vez que ambos mencionam o fato de cobrir perfeitamente o plano. A resposta mais completa de Gauss mostra também que o participante observa a relação entre os ângulos dos polígonos e a cobertura do plano sem sobreposição das formas. Assim, ao analisar as respostas dadas pelos dois participantes foi possível identificar que demonstram, no atual momento do curso, conhecer os princípios de formação e preenchimento dos ladrilhos, embora, de acordo com Santos (2014), essas propostas e discussões precisem ser mais aplicadas para comprovar sua eficiência, pois essas atividades fogem do padrão tradicional comum nas aulas de matemática.

Ainda no encontro 1, na atividade Conceitos do Geogebra, os participantes foram solicitados a construir polígonos regulares no Geogebra, a nomeá-los em relação ao número de lados e a determinar a medida de seus ângulos internos correspondentes. Ainda nessa atividade foram instigados a escrever sobre o que observaram a partir da construção finalizada.

Conforme mostram os procedimentos dos participantes na figura 1, o participante Lastonico, embora tenha realizado a construção de todos os polígonos solicitados e indicado nas figuras de forma correta as medidas de seus ângulos internos correspondentes, não os nomeou em relação ao número de lados. O participante Gauss, concluiu a tarefa adequadamente, pois destacou as medidas congruentes dos lados, apresentou os ângulos internos correspondentes e nomeou adequadamente cada polígono. 
Figura 1 - Construção de polígonos no Geogebra.

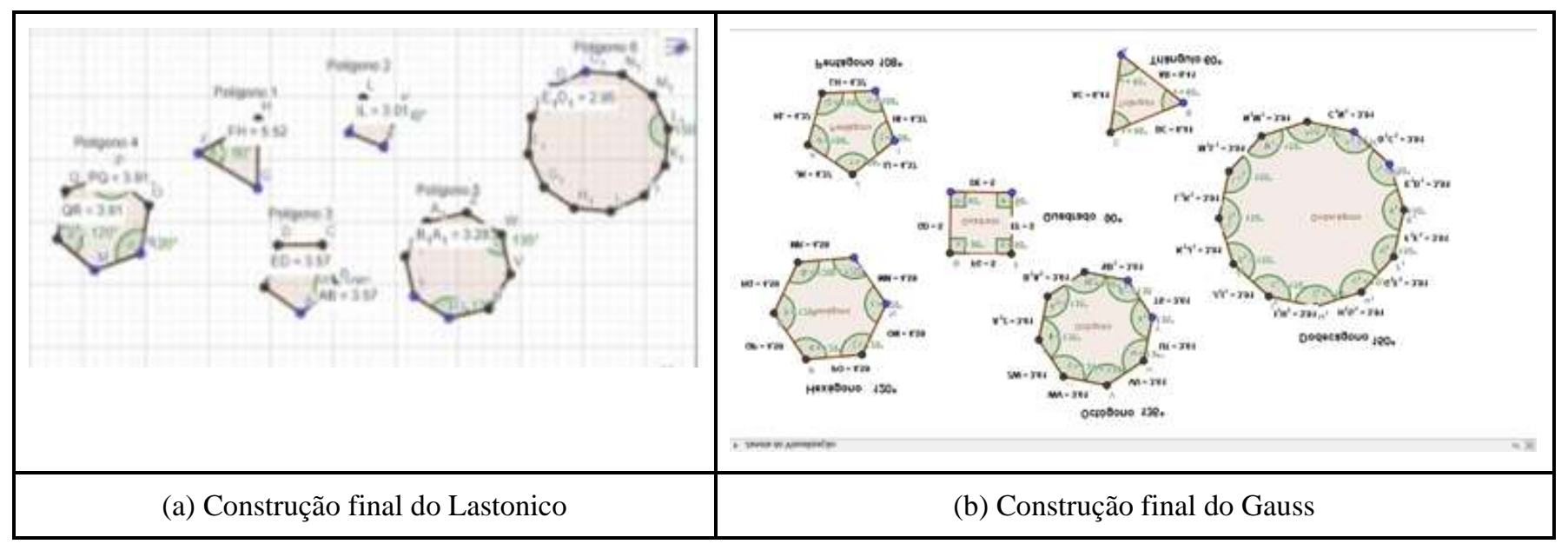

Fonte: Participantes (2021)

A respeito das observações dos participantes, Lastonico apontou que "Todos os ângulos internos são iguais, e a distância entre os vértices também”, enquanto o participante Gauss respondeu “Observo que cada um dos polígonos regulares, gerados no Geogebra, a partir dos vértices, possuem lados e ângulos iguais.

Das inferências possíveis a partir das observações dos participantes, Lastonico menciona que há uma relação de igualdade entre os vértices, no entanto, tal argumento não é válido e não permite afirmar que conceitos geométricos foram relacionados no desenvolvimento da atividade por Lastonico. A observação de Gauss, no entanto, permite inferir que há para esse sujeito uma compreensão que relaciona conceitos matemáticos geométricos à construção realizada pelo software, pois sua observação confirma a construção da figura com o apoio da ferramenta e confirma a relação de congruência entre os lados e ângulos internos de um polígono regular.

Cabe destacar que na análise a priori se propôs como previsão de respostas dos participantes para os questionamentos do encontro 1: os ladrilhamentos presentes em prédios históricos, em cozinhas e banheiros e a utilização de ladrilhos iguais para economia de materiais. E em relação à atividade Conceitos no Geogebra: a construção dos polígonos nomeados e seus ângulos indicados e a observação pelos alunos da definição de polígonos regulares de possuírem lados e ângulos congruentes. As respostas dos participantes confirmaram em parte essa previsão inicial, pois em alguns aspectos não foram conclusivas a respeito do conhecimento matemático evidenciado.

\subsection{Encontro 2}

No segundo encontro foram conduzidas as subseções denominadas de Manipulação e exercícios de ladrilhamento e Ladrilhamentos bem-comportados.

A subseção Manipulação e exercícios de ladrilhamento caracterizou-se pela realização de cinco questionamentos, sendo o primeiro: Quantos e quais foram os padrões de ladrilhamentos do plano que possuíam somente ladrilhos iguais? O participante Lastonico respondeu que "Pelo menos três: padrão 4 por 4 com quadrados, com triângulos 3.3.3.3.3.3, e com hexágono 6.6.6”. Já o participante Gauss, informou que "São três possíveis. Podemos agrupar em seis triângulos equiláteros, quatro quadrados e três hexágonos."

Analisando as respostas dos dois participantes é possível afirmar que ambas, embora parecidas, não são as mesmas, em razão da certeza do participante Gauss em relação às três combinações possíveis. No entanto, os dois participantes sinalizaram que entendem a lógica do padrão em torno de um vértice, referindo-se de forma correta às relações existentes na formação dos ladrilhamentos do plano com ladrilhos iguais, em relação ao número de polígonos e ao número de seus lados. 
Na questão 2 e 4 os alunos foram solicitados a inserir na plataforma do Geogebra Book as suas construções de ladrilhamentos com polígonos iguais e com polígonos diferentes, respectivamente, conforme mostra a Figura 2.

Figura 2 - Ladrilhamentos reproduzidos pelos participantes 1 e 2.

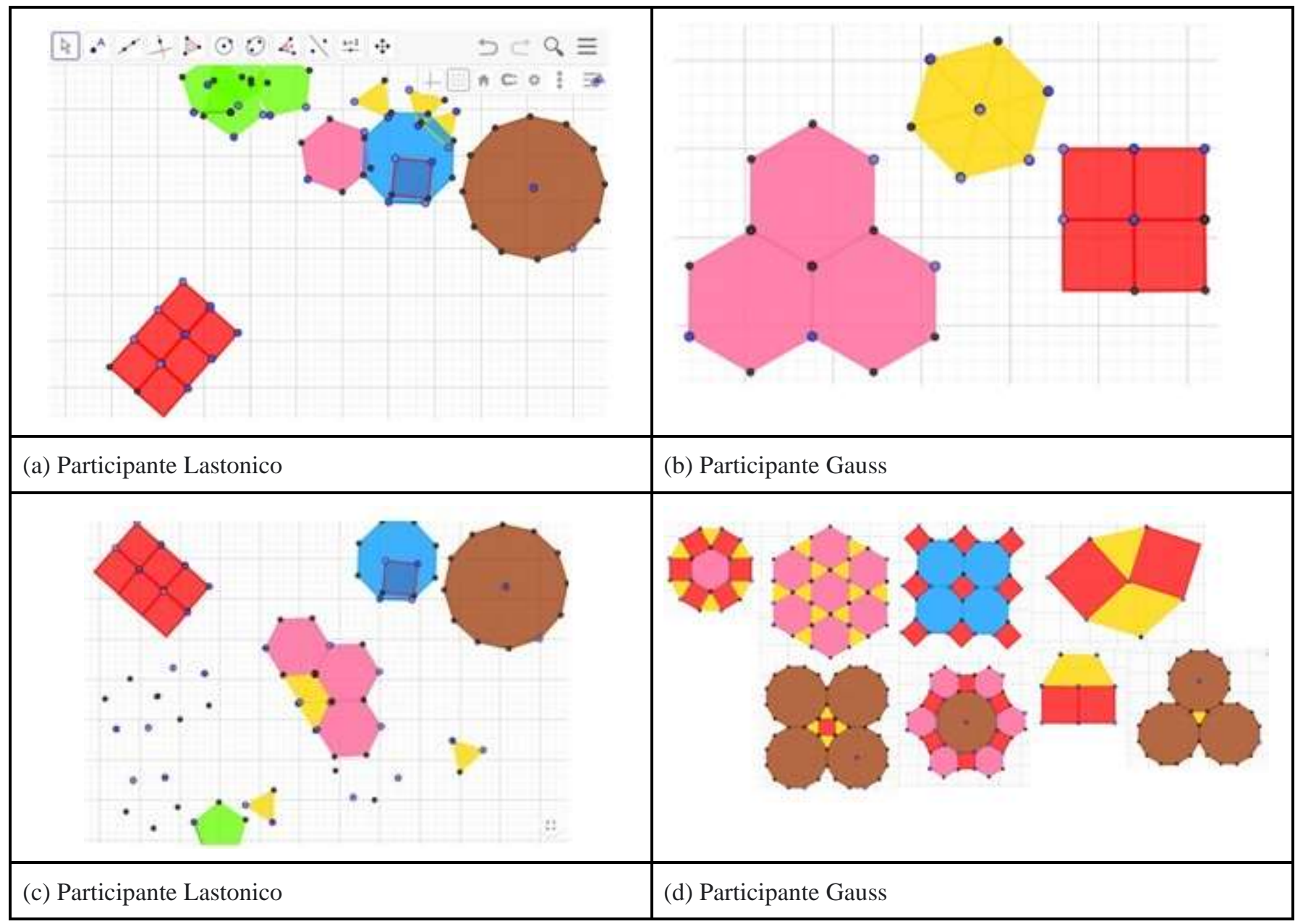

Fonte: Participantes (2021).

Para essa análise cabe examinar a imagem da Figura 2. Percebe-se que o participante Lastonico, na fig. 2a, apresentou apenas 1 ladrilhamento com uso de ladrilhos iguais e os demais polígonos da Figura 2a indicam que foram feitas tentativas que não foram finalizadas pelo participante. No entanto, na resposta dada na questão 1, esse participante demonstra conhecer pelo menos três composições possíveis. Por outro lado, a Figura 2b, com as representações elaboradas por Gauss, mostra que ele conseguiu representar e concluir os três ladrilhamentos com polígonos iguais mencionados na questão 1. Nessa direção é possível inferir que o uso do Geogebra para a composição das figuras pode ter influenciado nas composições do participante Lastonico.

Para a terceira questão: Quantos e quais foram os padrões de ladrilhamentos do plano formados com ladrilhos diferentes? Lastonico respondeu que "Pelo menos um, com hexágono e triângulo" conforme, observa-se na Figura 2c. Já Gauss disse: “Eu consegui realizar 8 padrões. Eles utilizavam: (Quadrado, triângulo, hexágono); (Hexágono e triângulo); (Octógono e quadrado); dois ladrilhos diferentes compostos por quadrados e triângulos; (Dodecágono e triângulo); (Dodecágono, triângulo e quadrado); (Dodecágono, hexágono e quadrado).” A imagem da Figura 2 ratifica a informação desse participante.

A análise mostrou que o participante Lastonico demonstrou conhecimento da manipulação de ladrilhos diferentes, mas não desenvolveu outros modelos, ou seja, representou apenas uma composição. Por outro lado, Gauss representou as oito 
combinações possíveis com ladrilhos diferentes, contudo na compreensão acerca dos padrões a serem explorados deixou dúvidas, uma vez que Gauss, embora tenha indicado a composição (Quadrado, triângulo, Hexágono) não retratou a formação em torno de um vértice, que seria 4,3,6,4, ou seja, dois quadrados, um triângulo e um hexágono em torno de um mesmo vértice. De forma análoga, quando Gauss menciona (Hexágono, triângulo) não se refere à formação 6,3,6,3 com dois hexágonos e dois triângulos, conforme visualizado na figura. Cabe mencionar que a posição dos números na sequência indica a ordem dos polígonos no ladrilhamento, conforme o número de lados do polígono. Nessa compreensão, Lastonico também não mostrou a posição e quantidade de ladrilhos na sua composição, mesmo estando correta a formação 6,6,3,3 mostrada na figura 2c.

Na questão cinco os alunos foram perguntados sobre: Qual é o princípio utilizado para preencher um ladrilhamento? Lastonico respondeu que "Os polígonos precisam ser regulares; a distribuição em volta de um vértice tem que ser a mesma". Nota-se que a resposta de Lastonico é insuficiente, pois nem toda formação com polígonos regulares preenche o plano. Para Gauss "O preenchimento será satisfeito se os ângulos formados pelos polígonos formam uma volta de $360^{\circ ”}$, o que está correto e permite inferir que conceitos matemáticos foram articulados e significados por esse participante na execução da atividade.

Na subseção Ladrilhamentos bem comportados foram realizados quatro questionamentos sobre se o comportamento dos ladrilhos bem-comportados.

Para o primeiro questionamento: 1- Todos os ladrilhamentos encontrados eram bem-comportados? - As respostas foram pontuais, Lastonico respondeu que não e Gauss disse que sim. Essas respostas foram fornecidas em função dos ladrilhamentos que eles representaram nas imagens da Figura 2.

Diante disso, nota-se que Lastonico ainda não construiu corretamente a percepção de ladrilhamento bem-comportado, conforme trabalhado no experimento com base em Caetano (2019). Por outro lado, Gauss ao responder que sim, ratifica a análise em torno de suas respostas e mostra a compreensão do conceito apresentado.

Para a questão 2: Quais foram os ladrilhamentos que não atenderam às três regras de bom comportamento. Por quê? o participante Lastonico respondeu que "O ladrilhamento de triângulo e hexágono ( 3 de cada), não atende à regra que diz que a distribuição de ladrilhos ao redor de cada um dos vértices é sempre a mesma". Gauss afirma que "Os compostos por pentágonos. Pois, o pentágono viola as condições para ladrilhos bem-comportados".

A resposta de Lastonico demonstra que há um equívoco em sua compreensão sobre o bom comportamento nos ladrilhamentos, pois a definição da distribuição de ladrilhos ao redor de cada um dos vértices do ladrilhamento ser sempre a mesma, significa que os ladrilhos serão os mesmos, repetindo-se na formação do padrão. Provavelmente não ficou claro para Lastonico que o ladrilhamento 3,3,3,6,6,6 significa que essa é a sequência de polígonos regulares repetidos ao redor de cada um dos vértices desse ladrilhamento.

Já Gauss descreve algo que não representou na figura 2, mas sua resposta demonstra conhecimento da definição de ladrilhamento bem-comportado, pois o exemplo dado pelo participante é de fato de um ladrilhamento que não atende à regra. Para a terceira questão: Quais foram os ladrilhamentos bem-comportados encontrados? - o participante Lastonico respondeu "O ladrilhamento de 4 quadrados. Porque atendem todas as condições". Já para Gauss "Os compostos por polígonos regulares obedeceram à regra de ladrilhos bem-comportados. Porque eles seguem as seguintes regras: Os ladrilhos devem ser polígonos regulares, de um ou vários tipos; A interseção de dois ladrilhos, se existir, é sempre um lado ou um vértice; A distribuição de ladrilhos ao redor de cada um dos vértices do ladrilhamento é sempre a mesma".

A resposta de Lastonico embora apresente um tipo de ladrilhamento bem-comportado está incompleta, pois todos os outros ladrilhamentos que atenderam as regras de bom comportamento poderiam ser citados. Cabe mencionar que a participante também poderia inferir a partir da soma $360^{\circ}$ dos ângulos ao redor de um vértice para apresentar outras respostas para a questão. Gauss respondeu de forma correta e conclusiva, demonstrando segurança na escrita completa dos princípios do 
ladrilhamento bem-comportado. quarta questão: Você conhece algum exemplo de ladrilhamento bem-comportado? Onde? busca uma relação com a realidade, que é imediatamente apresentada pelos participantes, pois Lastonico respondeu "Sim, 4.4.4.4. na cozinha", provavelmente relacionando às composições de pisos e azulejos, e Gauss, afirmou que "Eu vi alguns presentes em calçadas aqui na cidade de Bagé, mas não recordo quais ruas", remetendo-se a contextualização histórica trabalhada no primeiro encontro da experimentação.

Sobre as respostas esperadas para as atividades do encontro 2, ressalta-se que as expectativas são superadas em relação ao participante Gauss e parcialmente atingidas em relação ao participante Lastonico.

\subsection{Encontro 3}

No terceiro encontro, foi realizada a subseção denominada de Exploração dos conceitos matemáticos, esta caracterizou-se por seis questionamentos. O primeiro refere-se a: Qual é o número de lados (n), o número de triângulos a partir do vértice e, por fim, a soma dos ângulos internos de cada polígono? Responda para os seguintes polígonos regulares (triângulo, quadrado, pentágono, hexágono, octógono e dodecágono). Os participantes Lastonico e Gauss responderam, respectivamente, conforme Figura 3.

Figura 3 - Tabela respondida pelos participantes 1 e 2.

\begin{tabular}{|c|c|c|c|c|c|c|c|}
\hline$A$ & 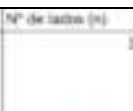 & 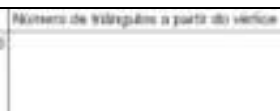 & 50 & $\begin{array}{l}\text { Poligonos } \\
\text { Regulares }\end{array}$ & $\mathrm{N}^{*}$ de lados $(n)$ & $\begin{array}{l}\text { Nümero de } \\
\text { triangulos a partir } \\
\text { do verticos }\end{array}$ & $\begin{array}{c}\begin{array}{c}\text { Soma dos } \\
\text { angulos internot }\end{array}\end{array}$ \\
\hline & 4 & & & & 3 & 1 & $180^{\circ}$ \\
\hline & & & & & 4 & 2 & $360^{\circ}$ \\
\hline & 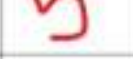 & 4 & & & 5 & 3 & $540^{\circ}$ \\
\hline & $b$ & 6 & & & 6 & 4 & $720^{\circ}$ \\
\hline & 7 & 7 & & & 8 & 6 & $1080^{\circ}$ \\
\hline & 12 & & & & 12 & 10 & $1800^{\circ}$ \\
\hline (a) Particip & te Laston & & & (b) Participan & Gauss & & \\
\hline
\end{tabular}

Fonte: Participantes (2021).

Nessa questão, os pesquisadores deixaram como exemplo as respostas relacionadas ao triângulo e os acadêmicos deviam responder a tabela com o número de lados (coluna 2), o número de triângulos a partir do vértice (coluna 3) e, por fim, a soma dos ângulos internos (coluna 4) dos polígonos quadrado, pentágono, hexágono, octógono e dodecágono (coluna 1). Essa questão exigiu que os acadêmicos reconhecessem que a soma dos ângulos internos de qualquer triangulo é $180^{\circ}$ e como cada polígono pode ser decomposto em triângulos. Portanto, bastava multiplicar o número de triângulos a partir de um vértice do polígno, por $180^{\circ}$ para descobrir o valor da soma dos ângulos internos do polígono correspondente (coluna 4).

Nota-se que Lastonico respondeu corretamente à questão para os polígonos quadrado e pentágono. Já os polígonos hexágonos, octógonos e dodecágono, ele responde parcialmente, conforme Figura 3a. Gauss responde corretamente as três colunas da tabela, conforme figura 3b. O uso da caneta e não da caixa de texto pode ter dificultado a escrita da resposta na 
tabela por Lastonico, pois é evidente que o acadêmico reconhece o processo de padronização ao preencher parcialmente os dados solicitados e ao reconhecer os elementos da fórmula na questão seguinte.

O segundo questionamento é: A partir da resposta anterior, generalize a fórmula e calcule a soma dos ângulos internos dos polígonos regulares: triângulo, quadrado, pentágono, hexágono, octógono e dodecágono?

Lastonico afirmou que: "diminuir dois do número de lados e multiplicar por 180.” Já Gauss respondeu que "A fórmula da soma dos ângulos internos está associada ao número de lados e também ao ângulo encontrado no menor polígono: $\mathrm{Sn}=(\mathrm{n}-2)^{*} 180^{\circ}$. Com isso, temos para cada polígono o seguinte: triângulo $\left(180^{\circ}\right)$; quadrado $\left(360^{\circ}\right)$; pentágono $\left(540^{\circ}\right)$; hexágono $\left(720^{\circ}\right)$; octógono $\left(1080^{\circ}\right)$; Dodecágono $\left(1800^{\circ}\right)$."

As respostas dos dois participantes, mostrou que ambos conseguiram encontrar as fórmulas, comprovando que entenderam os conceitos relacionados à fórmula da soma dos ângulos internos de um polígono. A descoberta da fórmula, corrobora que ela favoreceu o entendimento da questão, não por meio de uma explicitação pelo professor de uma fórmula préexistente à atividade, mas pela descoberta motivada por um processo de sistematização e busca de padrões que permitem chegar à fórmula.

É importante lembrar que o participante Lastonico respondeu parcialmente a tabela da questão 1, que foi elaborada com o intuito de conectar as duas primeiras questões e chegar ao reconhecimento dos elementos da fórmula da soma dos ângulos internos de um polígono, o que confirma nossa inferência anterior sobre o preenchimento parcial da tabela. Nesse sentido o objetivo almejado na análise a priori foi alcançado.

Na terceira questão: Determine a fórmula e calcule a medida dos ângulos internos dos polígonos regulares: triângulo, quadrado, pentágono, hexágono, octógono e dodecágono. O participante Lastonico respondeu "triangulo $1 * 180=180$; quadrado $2 * 180=360$; pentágono $3 * 180=540$; hexágono $4 * 180=720$; octógono $6 * 180=1080$; dodecágono $10 * 180=1800$." Enquanto Gauss afirmou "A fórmula da medida dos ângulos internos está relacionada com a da soma dos ângulos internos dividindo pelo número de lados. Sendo assim temos: a $=\left(180^{\circ *}(\mathrm{n}-2)\right) / \mathrm{n} . ”$.

Lastonico respondeu não generalizou a fórmula da medida dos ângulos internos solicitada, assim como, respondeu com dados que remetem à soma dos ângulos internos dos polígonos. Dessa forma, o participante demonstrou que ainda não consolidou o conhecimento objetivado com a atividade. Nesse sentido, caberia considerar a necessidade de outras abordagens, a fim de estabelecer relações necessárias para que o conhecimento seja ressignificado pelo participante. Já Gauss generalizou corretamente a fórmula, no entanto, não expôs as medidas dos ângulos internos de cada polígono, porém, ele sinalizou compreender bem o conceito matemático envolvido. Assim, admite-se como completa a resolução de Gauss, pois esse participante demostrou maturidade e rigor matemático em suas respostas até o momento.

A quarta questão refere-se a: Quais os ladrilhos iguais que preenchem perfeitamente o plano? - Para Lastonico as respostas são: "triangulo; quadrado e hexágono." E para Gauss, também.

Na previsão da análise a priori, esperava-se que eles resolvessem matematicamente a resposta, utilizando a expressão [(n-2).180] $\div$ e substituíssem o $n$ por números inteiros maiores que 2 e menores que 13. E os resultados que fossem números divisores de $360^{\circ}$ preencheriam o plano. Ao analisar as respostas, percebe-se que ambos os participantes responderam corretamente, no entanto, não é possível afirmar que o objetivo com a resposta esperada tenha sido alcançado, uma vez que a inserção dos ladrilhamentos com polígonos iguais foi trabalhada na questão 2 e pode ter interferido nessa resposta. Dessa forma, acredita-se que a manipulação e inserção dos ladrilhamentos no Geogebra contribuiu para que eles respondessem corretamente à questão e, com isso, caberia uma nova abordagem a fim de verificar a compreensão da relação entre os polígonos e os divisores de $360^{\circ}$ no ladrilhamento de um plano, o que pretende ser realizado para a versão final deste estudo.

$\mathrm{Na}$ quinta questão, perguntou-se o seguinte: Determine a fórmula e calcule os ângulos externos dos polígonos regulares triângulo, quadrado, pentágono, hexágono, octógono e dodecágono? 
Lastonico respondeu que "sabendo que a soma de um angulo inteiro com o externo tem que dar $180^{\circ}$, então: triangulo 180-60 = 120; quadrado 180-90=90; pentágono 180-108=72; hexágono 180-120=60; octógono 180-135=45; dodecágono 180150=30." Já Gauss afirmou que "A partir da utilização da fórmula da soma dos ângulos internos dos polígonos é possível verificar que para quaisquer polígonos regulares a soma será igual a $360^{\circ}$."

Os participantes Lastonico e Gauss não descreveram a fórmula, no entanto responderam corretamente em suas considerações. Faltou a ambos mencionar a relação entre o número de lados e a soma dos ângulos externos de um polígono regular, uma vez que essa é, conforme apresentado por Gauss, sempre $360^{\circ}$. Portanto, para encontrar a fórmula do ângulo externo de um polígono regular bastaria mencionar a relação $360 \%$. Considera-se, no entanto, que ambas as respostas estão corretas e demonstram que os participantes entenderam os conceitos.

A sexta questão é: A partir de todas as atividades que foram realizadas, como você define o conceito de ladrilhamento? Para Lastonico a resposta é "o angulo interno precisa ser divisor de 360". Enquanto Gauss, respondeu: "O ladrilhamento ocorre a partir do preenchimento de um plano sem deixar espaços em branco e sem ocorrer uma superposição dos polígonos."

Analisando essas respostas, percebe-se que o participante Lastonico não ampliou o conceito de ladrilhamento para polígonos diferentes, uma vez que para polígonos iguais, essa resposta é válida. Contudo, o ângulo interno não necessariamente precisa ser divisor de $360^{\circ}$, que são os casos do octógono e dodecágono, que tem $135^{\circ}$ e $150^{\circ}$, respectivamente, pois 2 octógonos e 1 quadrado, permitem ladrilhamento um ladrilhamento do tipo 8,8,4 ou ainda, dois dodecágonos e 1 triângulo, permitem um ladrilhamento do tipo $12,12,3$, além de outras composições que somam $360^{\circ}$ ao redor de um vértice, ou seja, cobrem perfeitamente o plano, sem deixar espaço e sem sobreposição. Portanto, Gauss respondeu corretamente.

Sobre as respostas esperadas para as atividades do encontro 3, destaca-se que as expectativas foram superadas em relação ao participante Gauss e parcialmente atingidas em relação ao participante Lastonico.

\subsection{Encontro 4}

No quarto encontro, foi feita a última subseção denominada de questionário pós-experimento, composta por sete questões, das quais neste recorte serão apresentadas as cinco primeiras questões, sendo a primeira: O que você achou das aulas sobre ladrilhamento e geometria plana? Por quê? A essa questão Lastonico respondeu: "Excelente, porque teve teoria na medida certa e a parte pratica foi bem interessante.". Para Gauss a resposta foi: "Boa, porque analisar os ladrilhamentos, da perspectiva geométrica, permite entender quais as características desse material, como os ângulos e quais figuras permitem realizar o ladrilhamento. Eu acredito que seja muito relevante trabalhar com esse contexto, pois facilita o entendimento do indivíduo para o estudo da Geometria Plana, e dos ângulos.".

Verifica-se nas suas respostas dos participantes uma boa receptividade a esse formato de atividade matemática, com caráter mais voltado para investigação e descoberta, contrapondo-se ao modelo mais expositivo. Durante os encontros foi possível perceber o engajamento dos acadêmicos em relação ao estudo e apropriação de conceitos matemáticos relacionados ao ladrilhamento, o que pode ser corroborado na resposta à questão 2.

Na segunda questão: O que você considerou fácil nesse experimento? - Lastonico respondeu que: "compreender os conceitos que envolvem a prática de ladrilhar." Já Gauss afirmou que: "Realizar os ladrilhos de polígonos iguais. Como os compostos apenas por triângulos, hexágonos e quadrados."

Mesmo com respostas distintas e alguma dificuldade maior demonstrada por Lastonico durante os encontros anteriores, no decorrer do encontro 4, os dois participantes demonstraram ampliação da compreensão dos conceitos iniciais, 
seja na visualização dos polígonos com suas medidas e relação entre ângulos, assim como, na constatação de que é necessário $360^{\circ}$ ao redor de um vértice para se obter um ladrilhamento, além de outras conjecturas apresentadas pelos participantes.

$\mathrm{Na}$ terceira questão os acadêmicos foram solicitados a descrever se: $\mathrm{O}$ uso da técnica de ladrilhamento facilitou sua compreensão dos ângulos e polígonos? E se você aprendeu a identificar melhor os conceitos de Geometria Plana depois dessas atividades? Lastonico mencionou que tal técnica o ajudou no entendimento. Percebe-se que ele concluiu com sucesso a etapa de "Exploração dos conceitos matemáticos", pois respondeu de forma satisfatória a todas as questões, reforçando tal entendimento. Em relação ao participante Gauss, pode-se afirmar que ele demonstrou domínio na compreensão e elaboração de conjecturas quando relacionados aos conceitos da Geometria Plana. Durante sua construção de ladrilhamentos com ladrilhos iguais (polígonos regulares iguais) e com ladrilhos diferentes (polígonos regulares diferentes), assim como em suas respostas no encontro referente a "Exploração dos conceitos matemáticos", Gauss encontrou as fórmulas solicitadas e fez observações pertinentes e teoricamente validadas em relação aos conceitos explorados.

Na quarta questão foram questionados: Em quais figuras planas você gostou mais de fazer ladrilhamentos e por que você gostou de trabalhar com essas figuras?

Lastonico respondeu que "foram as figuras triângulo e hexágono, por que aprendi conceitos novos." Já Gauss destacou que: "as figuras triângulo, quadrado e octógonos, porque as figuras planas menores possuem maior flexibilidade na construção desses ladrilhos. Quanto ao octógono, gostei do resultado do seu ladrilho, combinado com quadrados." As respostas dos dois participantes sinalizam para a aprendizagem de novos conceitos, o que fica mais explícito na afirmação de Gauss, uma vez que esse participante consegue relatar exatamente o que mais chamou atenção em sua produção de ladrilhamentos. Cabe acrescentar que o reconhecimento pelos participantes de um aprendizado novo remete a consolidação de conhecimentos, o que foi corroborado nas atividades concluídas pelos dois participantes, em maior ou menor nível de aprofundamento.

Na quinta questão foi perguntado se: Você encontrou dificuldade nas atividades propostas? Os participantes Lastonico e Gauss ambos responderam que não tiveram tais dificuldades. No entanto, cabe destacar que houve respostas parciais apresentadas por Lastonico, que podem ser devidas à uma dificuldade relativa, relacionada com a matemática e ou com o uso da ferramenta Geogebra.

Ao concluir esta análise, conclui-se que os participantes demostraram ampliação na compreensão de conceitos relacionados à Geometria Plana por meio da atividade de ladrilhamentos.

\section{Considerações Finais}

A Engenharia didática realizada, por meio de ladrilhamentos permitiu comparar conhecimentos iniciais e observar a evolução dos participantes ao longo do experimento realizado, desse modo, conclui-se que os estudantes alcançaram as respostas esperadas da sequência didática, bem como foi confirmada a hipótese de que através das atividades com a técnica de ladrilhamentos, o acadêmico é capaz de se aprofundar em conteúdos referentes à Geometria Plana. Nesse sentido, destaca-se que as previsões de respostas, em sua maioria, foram alcançadas ao longo das produções e discussões conduzidas durante o curso.

Conclui-se, portanto que a E.D. contribuiu para a ampliação e construção de conhecimento matemático geométrico, uma vez que no decorrer dos encontros foi possível detectar que os acadêmicos compreenderem de forma contextualizada a relação entre elementos de um polígono regular e sua aplicação na técnica de ladrilhamentos, assim como foram capazes de realizar conjecturas e generalizações representáveis por meio de afirmações e fórmulas.

Sugere-se para pesquisas futuras, a aplicação do método para outros públicos, como para alunos da Educação Básica ou cursos de formação de professores, destacando-se a possibilidade de encontros presenciais com objetos manipuláveis. Assim, almeja-se que este trabalho contribua para pesquisas futuras, para que cada vez mais alunos sejam estimulados a 
formular, empregar e interpretar a matemática em uma variedade de contextos, de forma a contribuir para a efetividade do seu aprendizado matemático.

\section{Agradecimentos}

À UNIPAMPA e ao Mestrado Acadêmico em Ensino (MAE) pela oportunidade de desenvolver esta pesquisa.

\section{Referências}

Afini, D. C. \& Souza Júnior, J. C. (2013). Mosaicos, pavimentações do plano e o ensino da geometria. Anais Encontro Nacional de Educação Matemática. http://sbem.iuri0094.hospedagemdesites.ws/anais/XIENEM/pdf/2842_780_ID.pdf.

Almouloud, A. S. (2007). Fundamentos da didática da matemática. UFPR.

Artigue, M.; Douady, R. \& Moreno, L. (1995). Ingeniería didáctica en educación matemática. Grupo Editorial Iberoámerica. https://www.researchgate.net/publication/277733635_Ingenieria_didactica_en_educacion_matematica.

Bogdan, R. C. \& Biklen, S. K. (1994). Investigação qualitativa em educação: uma introdução à teoria e aos métodos. Porto Editora.

Brasil. (2017). Ministério da Educação. Base Nacional Comum Curricular. http://basenacionalcomum.mec.gov.br/ima ges/BNCC_EI_EF_110518_versao final_site.pdf.

Brasil. (2019). Ministério da Educação. Base Nacional Comum para a Formação Inicial de Professores da Educação Básica. http://portal.mec.gov.br/docman/dezembro-2019-pdf/135951-rcp002-19/file.

Caetano, P. A. S.; Dias, C. C.; Sampaio, J. C. V. \& Rosa, M. B. (2010) A arte no plano: Confeccionando ladrilhos e construindo ladrilhamentos. UFSCAR. http://portaldoprofessor.mec.gov.br/fichaTecnicaAula.html?aula=20850.

Gil, A. C. (2002). Como elaborar projetos de pesquisa. Editora Atlas.

Gumieri, A. C. (2018). Aplicação da técnica de ladrilhamento com polígonos regulares nos anos finais do ensino fundamental. 100 f. Dissertação (Mestrado profissional em Matemática) - Programa de Pós-Graduação em Ensino de Ciências Exatas, Universidade Federal de São Carlos, São Carlos. https://sucupira.capes.gov.br/sucupira/public/consultas/coleta/trabalhoConclusao/viewTrabalhoConclusao.jsf?popup=true\&id_trabalho=6430569.

Julio, R. S.; Silva, G. H. G.; Nogueira, V. G. S. \& Oliveira, A. D. C. (2018). Ladrilhamentos e Educação Matemática. Boletim Online de Educação Matemática, 6(10). https://www.revistas.udesc.br/index.php/boem/article/view/11821.

Machado, S. D. A. (2012). Engenharia Didatica. In: Educação matemática: uma (nova) introdução. Editora da PUC.

Martins, R. S. (2018) Ângulos em polígonos: construindo mosaicos e ladrilhamentos. https://novaescola.org.br/plano-de-aula/1527/angulos-em-poligonosconstruindo-mosaicos-e-ladrilhamentos.

Mello, L. I. P. (2015). Ladrilhamentos no plano: uma atividade para o ensino médio. REMAT: Revista Eletrônica da Matemática, 1(2). https://periodicos.ifrs.edu.br/index.php/REMAT/article/view/1275.

Penteado, D. R.; Pereira, A. L. \& Brandt, C. F. (2019). Geometria no ensino fundamental: das exigências legais às práticas cotidianas. Revista Paranaense de Educação Matemática, 8(16). http://www.fecilcam.br/revista/index.php/rpem/article/vFiew/1854.

Pereira, L. R. (2017). Práticas de ensino em geometria plana. 174 f. Dissertação (Mestrado Profissional em Matemática em Rede Nacional) - Programa de Pós-Graduação em Matemática em Rede Nacional, Universidade Federal dos Vales do Jequitinhonha e Mucuri, Teófilo Otoni. https:e/sucupira.capes.gov.br/sucupira/public/consultas/coleta/trabalhoConclusao/viewTrabalhoConclusao.jsf?popup=true\&id_trabalho=5010188.

Sallum, E. M. (2016). Ladrilhamento. São Paulo: USP. https://www.slideshare.net/WilsonMarques8/ladrilahamento.

Santos, M. R. D. (2006). Pavimentações no plano: um estudo com professores de matemática e arte. 177 f. Dissertação (Mestrado em Educação Matemática) Instituto de Geociências e Ciências Exatas, Universidade Estadual Paulista, Rio Claro.

Santos, L. S. (2014). Ladrilhamento no Plano: Uma Proposta de Atividade para o Ensino Médio. 67 f. Dissertação (Mestrado Profissional em Matemática em Rede Nacional) - Programa de Pós-Graduação em Matemática em Rede Nacional, Universidade Estadual do Sudoeste da Bahia, Vitória da Conquista. http://www2.uesb.br/ppg/profmat/wp-content/uploads/2018/11/Dissertacao_LAZARO_SOUZA_SANTOS.pdf

São Paulo. (2009). Secretaria da educação. Caderno do professor: matemática, ensino fundamental: $6^{\circ}$ série. SEE.

Stefani, A. \& Proença, M. C. (2019). Análise das dificuldades de alunos dos anos finais do ensino fundamental na resolução de problemas de perímetro e área. Revista Paranaense de Educação Matemática, 8(16). http://www.fecilcam.br/revista/index.php/rpem/article/view/1902.

Teixeira, R. C. (2018). Uma maneira dinâmica de aprender área e perímetro de figuras planas a partir de situações concretas e lúdicas. 120 f. Dissertação (Mestrado em Matemática) - Programa de Pós-Graduação de Ciências e Tecnologia, Universidade Estadual do Norte Fluminense Darcy Ribeiro, Campos dos Goytacazes. https://sucupira.capes.gov.br/sucupira/public/consultas/coleta/trabalhoConclusao/viewTrabalhoConclusao.jsf?popup=true\&id_trabalho=6360927.

Universidade Federal do Pampa. (2017). Projeto Pedagógico do curso de matemática-Licenciatura. Bagé: UNIPAMPA. http://dspace.unipampa.edu.br/bitstream/riu/89/6/PPC\%20Matem\%c3\%a1tica_Bag\%c3\%a9.pdf.

Zanella, I. A.; Franco, V. S. \& Canavarro, A. P. (2018). Realizar construções geométricas com o geogebra: a contribuição do ambiente de geometria dinâmica para o futuro professor de matemática. Revista Paranaense de Educação Matemática, 7(14). http://www.fecilcam.br/revista/index.php/rpem/article/view/1706. 